\title{
Biography work in in long-term residential aged care with tablet support to improve the quality of life and communication - study protocol for app development and evaluation
}

\section{Biografiearbeit in Senioreneinrichtungen mit Tablet- Unterstützung zur Verbesserung der Lebensqualität und Kommunikation (BaSeTaLK) - Studienprotokoll zur App- Entwicklung und Evaluation}

\author{
Sabine Corsten ${ }^{1 *}$, Norina Lauer ${ }^{2}$ \\ ${ }^{1}$ Katholische Hochschule Mainz, Departement Gesundheit \\ und Pflege, 55122 Mainz, Germany \\ *corsten@kh-mz.de \\ 2Ostbayerische Technische Hochschule Regensburg, \\ Fakultät Angewandte Sozial- und Gesundheitswissenschaf- \\ ten, 93053 Regensburg, Germany
}

Received 13 November 2018, accepted 27 December 2019

\begin{abstract}
Background: Older adults in care facilities face a high risk of experiencing depression. The impact that early interventions like biographical work have on the quality of life for older adults in such facilities is unknown.

Aim: To develop and evaluate a tablet-supported intervention for biographical work in long-term residential aged care to increase the quality of life for older adults.

Design: The study will be conducted in a randomized pretest-posttest control group design with follow-up testing in group and single settings. Participants will be randomized to the experimental intervention (tablet-supported biographic work) or the control intervention (planned tablet-supported game playing), each guided by senior volunteers. A total of 80 residents and 16 volunteers will be recruited. The primary outcome for the residents and volunteers will be quality of life as measured with the World Health Organization Quality of Life Assessment-for older adults. Secondary measures will be self-esteem and life satisfaction. In addition, we will examine residents' ability to communicate and their functional independence.

Method: The first stage of the project involves developing an app. The app is developed in a user-centered, agile development process. It will use multimedia to prepare life history topics and links them to key questions. Next, a workshop is developed for the volunteers who accompany the use of the app in the institutions. During the second phase, biographic work stimulated by the app will be conducted in groups or individually with residents.

Discussion: This is the first known program tailored to older adults in care facilities and senior volunteers that aims to prevent depression by providing digitally supported biographic work.
\end{abstract}

\footnotetext{
Abstract

Hintergrund: Ältere Menschen in Pflegeeinrichtungen haben ein hohes Risiko, an Depressionen zu erkranken. Die Auswirkungen früher Interventionen wie Biografiearbeit auf die Lebensqualität älterer, institutionalisierter Personen sind unerforscht.

Ziel: Entwicklung und Evaluation einer tablet-gestützten Intervention zur Biografiearbeit in der stationären Langzeitpflege zur Steigerung der Lebensqualität älterer Menschen.

Design: Die Studie wird in einem randomisierten Pre-Test-Post-Test-Kontrollgruppen-Design mit Follow-up-Testung im Gruppen- und EinzelSetting durchgeführt. Die Teilnehmenden werden randomisiert der experimentellen Intervention (Tablet-gestützte biografische Arbeit) oder der Kontrollintervention (geplant Tablet-gestütztes Spiel), die jeweils von älteren, ehrenamtlich Helfenden unterstützt werden, zugewiesen. Insgesamt werden 80 Bewohner/-innen und 16 Ehrenamtliche rekrutiert. Primärer Outcome ist die Lebensqualität der Bewohner/-innen und der ehrenamtlich Helfenden, gemessen mit dem World Health Organization Quality of Life Assessment for older adults. Sekundärer Outcome sind Selbstwertgefühl und Lebenszufriedenheit. Darüber hinaus werden Kommunikationsfähigkeit und die funktionale Unabhängigkeit der Bewohner/-innen untersucht.

Methode: In der ersten Projektphase wird eine App im Sinne eines benutzerzentrierten, agilen Entwicklungsprozesses konzipiert, die multimodal lebensgeschichtliche Themen aufbereitet und mit Schlüsselfragen verknüpft. Für ältere Ehrenamtliche, die den Einsatz der App in den Institutionen begleiten, wird ein Workshop entwickelt. In der zweiten Phase wird die von der App angeregte biografische Arbeit im Gruppen- und Einzel-Setting durchgeführt.

Diskussion: Dies ist das erste bekannte Programm, das auf ältere Menschen in Pflegeeinrichtungen und ältere Ehrenamtliche zugeschnitten ist und darauf abzielt, Depressionen durch digital unterstützte biografische Arbeit vorzubeugen.
} 


\section{Keywords}

e-health - digitization - quality of life - biography work - long-term residential aged care - depression - voluntary work

\section{Keywords}

E-Health - Digitalisierung - Lebensqualität - Biografiearbeit - Altersheimbewohner/-innen - Depression - Freiwilligenarbeit

\section{BACKGROUND}

The starting point for the research project is the reduced quality of life that older adults experience in long-term residential aged care. Current surveys show that in 2015, 2.86 million people in Germany needed care as defined by the German Care Insurance Act (Sozialgesetzbuch, SGB XI), 83\% of whom were aged 65 and over. In total, $27 \%$ of all people in need of nursing care received care in long-term residential aged care (Statistisches Bundesamt, Federal Statistical Office, 2017). Estimates indicate that the number of people in need of nursing care will continue to rise to 4.5 million by 2050 (Stat. Bundesamt, 2017). The multimorbidity rate for people aged 70 and over is 88\% (Lindenberger et al., 2010). The physical changes associated with reduced mobility and communication restrictions are accompanied by reduced social exchange. In particular, institutionalized older people show reduced psychological well-being. More than 50\% suffer from emotional and social loneliness (Drageset et al., 2011; Luanaigh \& Lawlor, 2008), which is caused by the loss of loved ones and changes in their social situation as a result of moving into long-term residential aged care. Institutionalized persons complain about the lack of meaningful relationships (Roos \& Malan, 2012) and social support (Keister, 2006), the loss of meaning or identity (Saunders \& Heliker, 2008), and sadness (Fraher \& Coffey, 2011). A link between loneliness and dementia has also been shown (Luanaigh \& Lawlor, 2008). Loneliness and cognitive impairment, in turn, are considered the main predictors of depressive symptoms (Barg et al., 2006, see Review of Djernes, 2006). The prevalence rate for depressive symptoms increases from $33 \%$ for noninstitutionalized older adults (Mayer \& Baltes, 1999) up to $50 \%$ in institutionalized persons, while $20 \%-30 \%$ show severe depression (Balzer et al., 2013; Gaboda et al., 2011; Shahar et al., 2011; Weyerer \& Bickel, 2007). Especially in old age, depression results more frequently in physical diseases and a chronic course (Böhm et al., 2009) with an increased mortality rate (Freudenstein et al., 2001). Nevertheless, there are no systematic approaches to preventing or intervening depression in old age, especially for institutionalized older adults (Meeks \& Depp, 2003; Mosher-Ashley \& Lemay, 2001).

Biography work can promote adaptation processes in old age and, through this, support social participation and quality of life (Blimlinger et al., 1996; Gereben \&
Kopinitsch-Berger, 1998; Specht-Tomann, 2009). It is used to work on identity (e.g., Korte et al., 2012), based on guides for the work with individuals and groups (e.g., Kaiser \& Eley, 2016). Approaches focusing on activities are used alongside approaches focusing on narratives. Narrative-based approaches use life story telling to support identity (re)development. The reconstruction of one's own life story through interpersonal exchange stimulates identity negotiation processes and self-esteem and has a positive influence on the creation of meaning and coping with life (Moser, 2000; Ruhland, 2006). Biographical work is one of the quality characteristics of modern nursing care for the elderly (Specht-Tomann, 2009). It has a great potential for the prevention of mental pathologies, especially in older, institutionalized adults. A systematic review by Syed Elias et al. (2015) concludes that biographical work in retirement homes can counteract feelings of loneliness that manifest depression. However, there is sparse implementation in long-term residential aged care due to the increasing shortage of personnel, among other things (Stat. Bundesamt, 2017). When biographical work is used, it is usually reminiscence work for those diagnosed with dementia, but not to improve the quality of life of older people with no to slight cognitive impairments, who account for up to $50 \%$ of institutionalized persons (Schäufele Köhler et al., 2013). In a recent review, we identified 19 studies that investigate the effect of biographical work on older, cognitively healthy people in long-term residential aged care (Menn et al., 2019). Two controlled studies, in which memory work was used in a maximum of eight sessions, show significant improvements in quality of life and psychological well-being for residents with no or mild depression compared to the control groups (Chan \& Pang, 2010; Chiang et al., 2010). There are also indications of a lasting improvement in psychological well-being (Haight \& Michel, 2000). In a quasi-randomized study, Haslam et al. (2010) show that both individual and group sessions lead to significant improvement in quality of life of institutionalized older adults. To improve social integration, a group setting is highly recommended (Haslam et al., 2010; Housden, 2009).

Digital media offer the possibility of making independently conducted biographical work available to institutionalized seniors adapted to their cognitive and sensorimotor abilities (cf. Nordheim et al., 2015). However, in the health and social sectors, digitization is currently used for 
information and digital networking (e.g., Damodaran et al., 2014). Rehabilitation and teletherapeutic interventions are evaluated less frequently (Albrecht, 2016). There have been no systematic studies on digitally supported biographical work with older institutionalized adults (0 hits each with corresponding search in PubMed/ Cochrane). In a project with home residents suffering from dementia, tablets were used to stimulate communication and interaction by professional helpers (Nordheim et al., 2015). A lasting improvement in well-being was identified, and contact with relatives also intensified. Chan et al. (2016) were able to show that a tablet-based intervention led to cognitive improvements for the users. The authors underline the high practical benefit of tablets for older people, especially for overcoming social isolation and improving psychological well-being.

To promote digital inclusion, elderly care structures can be used in which older people support each other, from which digital learning benefits in a special way (Doh et al., 2016). So far, little research has been done on the promotion of digital inclusion of older people to increase social participation (Delello \& McWhorter, 2017). For older adults, social support seems particularly important for the sustainable use of digital media (Damodaran et al., 2014). Doh et al. (2016) stated that in digital learning in old age, the similarity of age between the mediator and the learner provides advantages in the social, emotional, and motivational areas. Thus, fellow seniors supporting elderly people in dealing with technology seems helpful. Biographical work, in turn, can also be carried out by guided voluntary group leaders if it is preventively oriented and structured by guiding questions and materials such as visualizations (Gibson, 2011; Housden, 2009). In a feasibility study, volunteers could adequately carry out systematic reminiscence work in people with dementia (Van Boegart et al., 2016). Furthermore, older volunteers were able to carry out systematic reminiscence work in palliative institutions with comparable success as trained persons (Allen et al., 2014). The volunteers experienced added value with an increasing sense of meaning and increased self-confidence (Allen et al., 2016). In a major survey, Anderson et al. (2014) conclude that older volunteers have greater social participation and better physical and cognitive health, with lower depression, dementia, and mortality rates. Technical support systems are again recommended to support volunteers in the implementation of biographical work (Allen et al., 2014). Using volunteer's potential can thus make a meaningful contribution to linking biographical work and digitization.

The overall aim of the BaSeTaLK project is to improve the quality of life of institutionalized older adults by developing and evaluating tablet-based biography work. This is associated with the prevention of reduced psychological well-being and manifest depression. The project also seeks to achieve more social participation and communication. The software (app), which will be adapted to the needs of older and very old adults, is intended to stimulate biographical conversations. Specific adaptations to the communicative and cognitive abilities of older adults will be taken into account. Speech therapy expertise as well as knowledge from nursing sciences will be used for this purpose. Closely linked to the first aim is the implementation of the app to promote independent exchange of older people. To this end, volunteer seniors will be introduced to the app and basic questioning techniques, so that they can accompany the work in the institutions. A further goal is to gain knowledge on how digitization can be used to promote participation for older people and which factors can contribute to successful interactions. This participatory research approach, in addition to regular usability studies, will provide scientists with insights into the human-media interface in the health and social sectors.

The study contributes to digitally supported health promotion in gerontological practice. The autonomously initiated communicative exchange can relieve the burden on nursing staff. After completion of the study, the nursing staff of the participating institutions will receive training in tablet-supported biographical work, so that they can carry out appropriate training for other senior citizens on the basis of the knowledge gained in order to continue the intervention. Overall, an economic benefit could be achieved at low cost in the sense that therapists and nursing staff would be involved to a lesser extent and older persons and volunteers would have to use fewer help services due to sustainably improved living conditions. The first phase of the BaSeTaLK intervention program is developing an app. Senior citizens will be consulted in the sense of a user-centered, agile development process. Thus, the concept will be developed and validated in a 'Design Thinking Mode' (Häger et al., 2015). Furthermore, a workshop will be developed for older volunteers who accompany the use of the app in the institutions. In the second project phase, the app's use in a group setting in various institutions will be evaluated in a randomized pretest-posttest control group design with a follow-up test. Additionally, its use in an individual setting will be evaluated in a pretest-posttest design with a follow-up test.

\section{HYPOTHESES}

\section{Primary hypothesis}

Residents who receive the BaSeTaLK intervention as well as volunteers who help with the intervention will have significantly better outcomes in quality of life 
tx: testing points

t1-t0: critical interval to determine intervention effects

IG: intervention group; CG: control group

modification app takes place after the group intervention,

individual intervention starts during the intervention-free phase for the groups

Group intervention

\begin{tabular}{|c|c|c|}
\hline $\begin{array}{l}\text { workshop } \\
\text { volunteers }\end{array}$ & $\begin{array}{c}\text { 3-month } \\
\text { intervention } \\
8 \text { IG \& } 8 \text { CG }\end{array}$ & $\begin{array}{l}\text { 3-month } \\
\text { intervention-free } \\
\text { phase }\end{array}$ \\
\hline & & \\
\hline
\end{tabular}

$\underline{\text { Individual intervention }}$

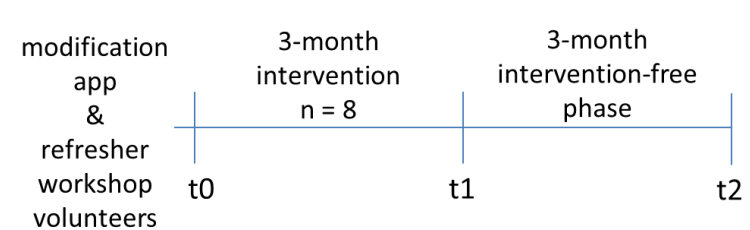

Figure 1: Study design.

(Conrad et al., 2016) immediately after the intervention as compared to the baseline.

\section{Secondary hypothesis}

Participating residents and volunteers will have significantly better outcomes on measures of selfesteem (Collani \& Herzberg, 2003) and life satisfaction (Wiendieck, 1970) immediately after the intervention as compared to the baseline. In addition, residents who complete the BaSeTaLK intervention are hypothesized to have a significantly better score on a communication activity measure (Lomas et al., 1989) and in functional independence (Mahoney \& Barthel, 1965) as compared to the baseline.

\section{METHODS}

\section{Design}

The project has two central work phases. The focus of the first 12-month phase is on developing the app and planning the workshop for the volunteers. In the second phase, the workshop will be carried out and the tabletsupported biography work will be evaluated first in a group setting and then in an individual setting.

The study design is depicted in Figure 1. The evaluation will take place in a randomized pretest-posttest control group design with an observation period of 3 months and with a follow-up assessment after another 3 months. We expect a statistically significant change immediately after the intervention. With the follow-up examination, the stability of the effects will be examined. With the help of the app, eight groups of four to five participants each will conduct biographical conversations once a week for 3 months, for a total of 12 meetings. Volunteers will be introduced to the tablet and tablet-supported biography work in a 1-day workshop, so that they will be able to moderate the groups. At the same time, it is planned that eight control groups with four to five participants each will work with game apps. Control groups will also be supported by volunteers who will train the operation of the game apps in a 4-hour workshop. In order to balance setting influences, an intervention as well as a control group will be examined in each care facility. A total of up to 80 participants and 16 volunteers will be included. Following the group intervention, the app will be adapted based on the group's experience and the eight volunteers of the intervention groups will receive a 'refresher workshop' for doing the individual interventions. If volunteers from the group interventions can no longer be integrated into the individual interventions, further volunteers and/or interested participants from the group interventions will receive an all-day workshop to carry out the individual intervention. Building on the halfday (refresher) or full-day workshop, they will use the procedure once a week for 3 months with one resident each (total $n=8$ ) who cannot participate in group meetings due to immobility. The evaluation will take place in a pretest-posttest design with follow-up for stability examination after 3 months without a control group. Therefore, we will initially only examine the applicability of the approach to severely impaired people.

Recommendations for Interventional Trials (Standard Protocol Items: Recommendations for Interventional Trials [SPIRIT]) 2013 statement (Chan et al., 2013) 
have been used to develop the trial protocol. We use the Template for Intervention Description and Replication (TIDieR) guide (Hoffmann et al., 2014) for description of the study interventions.

\section{Participants: inclusion and exclusion criteria}

In accordance with Allen et al. (2014), we use the following inclusion criteria to select volunteers. Persons must have at least an intermediate level of education and sufficient German language skills; they also must be mobile and participate in the 1-day workshop to be included. The maximum cognitive impairment of program participants should be slight, which corresponds to a value of $\geq 20$ in the Mini-Mental status test (MMST; Folstein et al., 1990). This ensures that the intervention can take place without close professional support. Also, depression should not be advanced, that is, a value $\leq 8$ on the Geriatric Depression Scale (GDS; Sheikh \& Yesavage, 1986), since a preventive intervention is being evaluated here. Psychological support will be consulted for participants with GDS values between 5 and 8. Furthermore, for the group, participants should not occupy a nursing care bed. For bedridden residents, individual intervention is offered. Since the activation is multimodal, further criteria regarding auditory or visual impairments are not necessary (see also Haslam et al., 2010). In addition, as many participants as possible should be included in order to test the broad applicability of the method. Persons who do not meet the above criteria are excluded from participating.

Senior citizens' facilities of leading institutions in the Rhine-Main and Upper Palatinate regions of Germany (Caritas, Arbeiterwohlfahrt, Seniorenamt) are included. Facility staff will identify potential residents. Project staff, that is, speech pathologists, will check the potential residents for eligibility based on the inclusion/exclusion criteria. Volunteers will be recruited through municipal institutions and regional Internet and PC initiatives for older adults. Each potential resident or volunteer will be provided with a written participant information sheet and consent form and will be given a verbal explanation of the research. The participant's capacity to decide whether to participate will be judged by project staff members (trained in communicating with and verifying comprehension of older adults).

\section{Randomization}

A factor that may affect the outcome of this study is the type of facility in which the participants live. Hence, each facility will provide the experimental as well as the control intervention. As part of the informed consent, participants are informed that the trial comprises an experimental group condition and a control group condition. Participating residents as well as volunteers who agree to participate will be randomized to either the experimental intervention or the control intervention, stratified according to care facilities, by a randomization procedure using a computer-generated random number scheme. Thereby, sequential numbers will be assigned to each participant within each facility.

\section{App development}

An app will be developed for mobile devices and tablets (iOS and Android). For reasons of data protection, groups should be able to use the app offline, which prevents users' personal data from being passed on to external services.

A user-centered, agile development process will be used to develop the app for this study. Lean UX and 'Design Thinking' are preferred for the structured finding of innovative solutions to the given problems and for the rapid development and validation of prototypes (cf. Brenner \& Uebernickel, 2016; DIN ISO 9241-210, 2010; Gothelf, 2012; Hägernet al., 2015; Molich et al., 2018; Warfel, 2009). Furthermore, an agile project management with Scrum will be applied (e.g., Cohn, 2009). DT@ Scrum is a framework (Häger et al., 2015) that describes the transition from creative and explorative phases of a project to a structured agile development. In the 'Design Thinking Mode', the iterative development of the concept will take place with increased feedback from the users. This phase will see the development of an interactive click dummy of the app. In the 'Fully Integrated Mode', a prototype will be designed and evaluated in usability tests. The development phases will be accompanied by six focus group meetings in a senior citizens' facility, in which two residents and two volunteers will participate in addition to the scientific staff of the project.

A five-resident reference group in a senior citizens' facility will test the app's usability. Usability will be measured according to formal (design, interaction gestures, icons, writing) and content-related (topics, Internet research) criteria by observing a test run and evaluating subsequent short interviews. Here, changing the font size, making the menu and function selections clearer, eliminating redundant buttons, colors, and input options could all be relevant. With regard to content, the topics should be perceived as meaningful and inspire reflection. Participatory research in the field of e-Health and older adults shows that an early involvement of the target group can increase the fit and acceptance of the software (Frennert \& Östlund, 2016).

Adjustments will be made during the development phase on the basis of pilot tests and after group interventions, if necessary, for the individual intervention. During the group intervention, only technical errors will be 
corrected. The group interventions are thus comparable, but comparability with the individual intervention is not given. Here, however, it should be considered that the group setting generally has other aspects than an individual setting, for example, the group dynamics that will influence the use of the app.

\section{App content}

For biographical work, the app offers the same structure for each topic. Participants will be asked one question each on the past, present, and immediate future, which are discussed one after the other in the group or individual setting. Subsequent topic-specific Internet research involving all participants, such as the search for one's own birthplace, might follow. The joint Internet research has a motivating and positive effect on group dynamics in the sense of a jointly solved task (Nordheim et al., 2015). The group or individual participant will choose the topics as an adapted learning situation. Communication stimulation will be multimodal: For example, contextrich photos (Beukelman et al., 2015) introduce the topics and pictograms augment communication. Topic-specific questions are both written and audible, which should support the volunteers in their moderation and reduce their preparation time. The app serves the volunteers who use the tablet for the group as a structuring and communication aid.

Using the topic 'Family' as an example, the work with the app will be illustrated: The topic can be opened with a prototypical photo of a family. The following questions can be asked about the past: 'What did you like to do with your family in the past?', the present: 'Who belongs to your family?', and the future: 'What would you like to do with your family when they come to visit you?'. All questions will be presented in written and audible form. The questions are intended to stimulate conversation in the group. If the first question leads to an extended discussion, further questions may not be discussed. Supporting pictograms can be exemplary pictures of grandchildren and so on. If participants are not able to express themselves well, they can point to the pictograms. Further topics can be hobbies, health, and so on.

\section{Workshop concept}

In the 1-day workshop, which is based on an actionoriented approach (Gudjons, 2008, see also Arnold \& Gomez-Tutor, 2007; Arnold \& Schüßler, 2010), volunteers will be imparted with technical and media skills as well as knowledge of biography work and moderation of small groups. This will be followed by impulse lectures on information transfer, group work, and role playing for exercising and reflecting behavior. Based on Allen et al.'s concept (2014), which was used to prepare volunteers in palliative care, the workshop will present and discuss a checklist for observing residents' emotions. In the sense of a 'stepped-care program', volunteers will be instructed to refer the residents to further offers of help if necessary (see Dozeman et al., 2012). In a 4-hour 'refresher workshop', the volunteers will prepare for the individual interventions after the group intervention. New volunteers will be offered the 1-day workshop.

The technical and media skills for using the game apps in the control groups will be taught in a 4-hour workshop.

\section{Intervention}

Following the workshop, the intervention and control groups will meet 12 times: once a week for approximately 60 minutes in the senior citizens' facilities. In the meetings, the groups will work on a biography-relevant topic with the app (see the section 'App content'). The guiding principle derived from the biographical work is that past, present, and future are illuminated on each topic. In addition to the questions from the app, further questions such as resource-oriented questions can be asked, which will be practiced during the workshop. If possible, all group participants should be included in the discussion. The last meeting of the intervention groups will be filmed in order to define target criteria, which, according to the literature, have a motivating effect (Gibson, 2011). At the end, the groups will receive the video as a result. In addition, each participating resident will receive a kind of 'biography booklet', in which each resident briefly notes the relevant topics of the meeting at the end of each session.

After a refresher or full-time workshop and possible adjustments to the app, the individual interventions begin with mobility-impaired residents, who follow the group session schedule in the individual setting. The last individual session is again documented in writing according to the wishes of the residents, so that a final result is also achieved here.

In the control groups, which are also supported by a volunteer for 12 appointments each, game apps could be used, for example, 'Who wants to be a millionaire?'. The volunteer can guide through the app, read the questions aloud, and click on the answers. The possible answers can be discussed in the group. The helpers are instructed to prevent more in-depth biographical conversations as far as possible.

The same volunteer works with the same group or individual resident over the entire time to exclude the effects of changing people. It is known that the therapeutic relationship, that is, the cooperation and emotional bond between volunteers and sharing seniors in our study, affects the intervention (Horvath \& Bedi, 2002). Changing 
volunteers as group and individual facilitators could, also due to different characteristics of different volunteers, impair the process of building trust or getting engaged in the intervention. In acute problematic situations, however, the nursing staff designated as contact persons in the cooperating institutions can be contacted. Each group or individual is additionally assigned a researcher from the project who can be contacted to discuss problem situations. Before and after each group meeting, the research assistants will contact the senior volunteers to discuss the meetings before and after. In this context, a possible stress situation of the volunteers is also addressed. If volunteers feel excessively burdened, they will receive support from the research assistants or, if necessary, can cancel their participation in the program.

\section{Primary outcomes}

The primary outcome for the residents and volunteers will be the quality of life. It will be determined with the World Health Organization Quality of Life Assessmentfor older adults (WHOQOL-OLD; Conrad et al., 2016), as this is specifically aimed at older people and has already been used in evaluation studies (e.g., Ecran-Sahin \& Nuran Emiroglu, 2018).

\section{Secondary outcomes}

The WHOQOL-OLD is usually used in combination with the World Health Organization Quality of Life Brief Version (WHOQOL-BREF; Conrad et al., 2016) for the examination of elderly people, as the instruments complement each other, and thus cover all relevant areas of life in old age. The evaluation is carried out separately. Thus, as a secondary outcome, the quality of life is measured with the WHOQOL-BREF. Further secondary outcomes for the participating residents and volunteers will be the impact on self-esteem as measured by a German version of the Rosenberg Self-Esteem Scale (SES; Collani \& Herzberg, 2003) and life satisfaction as measured by the A-Form Life Satisfaction Index (LSI-A) of Neugarten, Havighurst, and Tobin (German version: Wiendieck, 1970). For residents, the effects on functional independence and the ability to communicate will be examined with the Barthel Index (Mahoney \& Barthel, 1965) and the Communicative Effectiveness Index (CETI; Lomas et al., 1989), respectively.

\section{Blinding}

The primary and secondary endpoints will be independently scored from the study assessors performing the pre- and post-intervention assessments. That is, the scoring will be performed by the other staff members who are experienced in administration and scoring. Thus, the assessors and the scorers will be different employees, but both of them work in the project. However, rules will be established in advance to ensure that the assessors and analysts do not discuss the investigations. The scorers will only receive an anonymous copy of the test forms, which they then evaluate. They will be blinded to group allocation (experimental, control) and testing session (baseline, post-test, or follow-up). Unblinding of the outcome scorers will not result in discontinuation of a participant's involvement in the study. Attempts will be made to replace the outcome scorers if unblinding occurs and re-administration will occur.

\section{Additional data collection}

\section{Qualitative data}

Immediately following the group intervention, all volunteers and one participating resident from each intervention group will share their perspective on the intervention and their own life situation with recorded, semi-standardized individual interviews. After the individual interventions, four randomly selected participants and four randomly selected volunteers will be asked about their experiences with semi-standardized interviews.

\section{Usability test}

In order to evaluate the use of technology, participatory observation by project staff will take place in the 6th and 12th meetings of the group interventions. Specific questionnaires based on usability checks will be used in the development (see the section 'App development') and application phases, at the end of both the group and individual interventions.

\section{Fidelity}

To ensure adherence to the protocol and comparability of the implementation, the volunteers should complete a checklist after each group and individual meeting (e.g., who participated, which topic was chosen, etc.; see e.g., Dixon \& Johnston, 2010). Workshop fidelity will also be controlled for by video recordings, which will be evaluated with a checklist.

\section{Data management}

A data management plan has been created via DMPonline. Synology Cloud Station Drive, which enables data storage on a server of the OTH Regensburg, will be used for secure data exchange between the network universities. 
The network uses this cloud solution already for another research project. Project staff from each university will enter anonymized participant data directly into Synology Cloud Station Drive. Once data collection has commenced, the study's chief investigators will monitor data for completeness and accuracy. They will also monitor the progress of the study, adverse safety events, as well as audit data accuracy on an ongoing basis. No formal criteria exist for discontinuing the trial early.

\section{Power calculation}

The sample size for the primary outcome was set based on the group intervention. The statistical power was calculated with $\mathrm{G}^{*}$ Power. We used the t-test for differences between two independent means. The input parameters were one-tailed calculation with an alpha error of 0.05 and a power of 0.8 because of the exploratory character of the study. The allocation ratio was 1 . A minimum sample size of 30 persons is required to detect an effect of 0.65 . Strong effect sizes of 0.8 are necessary for a group of 21 persons. Based on mean to strong effect strengths, eight target and eight control groups of four to five persons each should achieve a sufficiently large sample, even assuming at least $15 \%$ dropout (Haslam et al., 2010). In the light of the setting and manageability of the groups, larger or more groups do not appear to be practicable. Since the individual intervention is purely indicative, no power calculation is used here.

\section{Analysis}

Inferential statistics of intra-individual changes and interindividual differences as well as group differences will be evaluated after testing for normal distribution either with nonparametric or parametric procedures with the IBM SPSS 25.0 statistics program. The study data, which refer to the effectiveness of the intervention, will be evaluated as a pre-post analysis with an observation period of 3 months. The metric variables will be analyzed according to the distribution characteristics by means of a t-test for connected samples or Wilcoxon test. In addition, regression analyses and the Kruskal-Wallis $\mathrm{H}$ test will be used. The number of factors will depend on the extent to which the recorded group differences represent a homogeneous or nonhomogeneous construct. Cluster analyses or latent class analyses can be used to identify the subgroups. For example, influencing factors such as age, gender, morbidity, and length of stay in the care facility can be analyzed. An alpha level of 0.05 will be accepted as significant. The results of the statistical models will be presented in the form of regression coefficients, their $95 \%$ confidence intervals, and effect sizes.
Evaluation of the qualitative data will take place based on qualitative content analysis (Mayring, 2015). Percentage scores will be determined for the checklists for protocol adherence and Kappa statistics calculated to determine inter- and intra-rater reliability. Since the data on protocol reliability will be evaluated at intervals according to their availability, they can be used to improve the workshop and the sessions (cf. Behn et al., 2018).

\section{DISCUSSION}

This is the first known tablet-supported, biographicoriented intervention that aims to improve quality of life and prevent depression in older adults in longterm residential aged care without severe cognitive impairment. The intervention is of reasonable intensity and duration and requires support from volunteers. If effective and integrated into current practice, it has the potential to improve quality of life and psychological well-being, in addition to other functional outcomes impacted by psychological well-being. The approach will optimize the care of older adults in terms of autonomy and quality of life in the field of e-Health, and factor in the expertise of the health care professions.

By training speech therapists, occupational therapists, social workers, and carers, who can serve as multipliers and, in turn, instruct volunteers, the approach can be continued, disseminated, and established in the cooperating institutions. The methodical implementation via the app and its publication via open source are intended to ensure that the approach and the adapted materials, as evaluated, can be used. In this way, the method could contribute to relieving the workload of nursing staff, which is particularly appropriate in view of the increasing shortage of personnel (Stat. Bundesamt, 2017).

\section{Trial status}

The project started in August 2019 and the first focus group meetings are planned for January 2020. The project is officially registered and can be viewed on the public website of the German Register of Clinical Trials and on the World Health Organization's search portal (http://apps.who.int/trialsearch/). Three care facilities have been recruited, including Caritas-Altenzentrum Albertus-Stift, Gau-Algesheim, Caritas-Altenzentrum Maria König, Mainz, and AWO Altenzentrum Konrad-Arndt, Wiesbaden. Furthermore, cooperation agreements have been reached with the 'Seniorenamt' (Senior Citizens' Office) of Regensburg, the 'FreiwilligenAgentur' (Voluntary Agency) Regensburg, and the 'Gerontopsychiatrische Koordinationsstelle 
Oberpfalz' (Gerontopsychiatric Coordination Office, Upper Palatinate), which offer access to volunteers as well as to care facilities.

\section{ACKNOWLEDGEMENTS}

The trial sponsor is the Federal Ministry of Education and Research (grant from 2019-2022, 13FH515SA7, 13FH515SB7). We thank Kevin Frac for the linguistic correction and the reviewers for their helpful comments which helped to improve the paper.

An ethical approval was received from the Ethics Committee of the German Society of Nursing Science (reference: 18-019), and an ethics advisory board of three

\section{ETHICS APPROVAL}

experts has been set up representing external scientific expertise in the fields of digitization, communication sciences, medicine, philosophy, and psychology. Once a year, the Ethics Council will receive an interim report on ethical and data protection aspects of the project and will be involved at short notice in any questions that will arise. Iterative development of the app, including the target group of older adults, involves the challenges of integrating aspects into the app which cannot be anticipated and which must first be checked and secured under data protection law at short notice.

\section{CONFLICT OF INTEREST}

None.

References

Albrecht, U.-V. (2016). Kapitel Kurzfassung. In: Albrecht, U.V. (Ed.), Chancen und Risiken von Gesundheits-Apps (CHARISMHA) (pp. 14-47). Medizinische Hochschule Hannover, urn:nbn:de:gbv:084-16040811173. Retrieved from: http://www digibib.tu-bs.de/?docid=60004 (Stand: 22.08.2018).

Allen, R.S. et al. (2016). "It Was Very Rewarding for Me ...": Senior Volunteers' Experiences With Implementing a Reminiscence and Creative Activity Intervention. Gerontologist, 56(2), 357-367.

Allen, R.S. et al. (2014). Can Senior Volunteers Deliver Reminiscence and Creative Activity Interventions? Results of the Legacy Intervention Family Enactment (LIFE) Randomized Controlled Trial. Journal of pain and symptom management, 48(4), 590-601.

Anderson, N.D. et al. (2014). The benefits associated with volunteering among seniors: A critical review and recommendations for future research. Psychological Bulletin, 140(6), 1505-1533.

Arnold, R., \& Gomez-Tutor, C. (2007). Grundlinien einer Ermöglichungsdidaktik: Bildung ermöglichen - Vielfalt gestalten. Augsburg: Ziel Verlag.

Arnold, R. \& Schüßler, I. (2010). Ermöglichungsdidaktik. Baltmannsweiler: Schneider Verlag Hohengehren.

Balzer, K., Butz, S., Bentzel, J., Boulkhemair, D., \& Lühmann, D. (2013). Beschreibung und Bewertung der fachärztlichen Versorgung von Pflegeheimbewohnern in Deutschland. In Deutsches Institut für Medizinische Dokumentation und Information (Ed.), Health Technology Assessment (HTA) In der Bundesrepublik Deutschland. Köln: DIMDI.

Barg, F.K., Huss-Ashmore, R., Wittink, M.N., Murray, G.F., Bogner, H.R., \& Gallo, J.J. (2006). A Mixed-Methods Approach to Understanding Loneliness and Depression in Older Adults. The Journals of Gerontology. Series B, Psychological Sciences and Social Sciences, 61(6), S329-S339.
Behn, N., Hilari, K., Marshall, J., Simpson, A., Northcott, S., Thomas, S., Flood, C., Goldsmith, K. \& McVicker, S. (2018). SUpporting well-being through PEeR-Befriending (SUPERB) trial: an exploration of fidelity in peer-befriending for people with aphasia, Aphasiology, 32(sup1), 21-23.

Beukelman, D.R., Hux, K., Dietz, A., McKelvey, M., \& Weissling, K. (2015). Using Visual Scene Displays as Communication Support Options for People with Chronic, Severe Aphasia: A Summary of AAC Research and Future Research Directions. Augmentative and Alternative Communication, 31(3), 234-245.

Blimlinger, E., Ertl, A., \& Koch-Straube, U. (2000). Lebensgeschichten. Hannover: Vincentz.

Bogaert, Van P., Tolson, D., Eerlingen, R., Carvers, D., Wouters, K., Paque, K., Timmermans, O., Dilles, T., \& Engelborghs, S.J. (2016). SolCos model-based individual reminiscence for older adults with mild to moderate dementia in nursing homes: a randomized controlled intervention study. Journal of Psychiatric and Mental Health Nursing, 23(9-10), 568-575.

Böhm, K., Tesch-Röhmer, C., \& Ziese, T. (2009). Gesundheit und Krankheit im Alter. Eine gemeinsame Veröffentlichung des Statistischen Bundesamtes, des Deutschen Zentrums für Altersfragen und des Robert Koch-Instituts. Retrieved from: https:// www.destatis.de/GPStatistik/servlets/MCRFileNodeServlet/ DEMonografie_derivate_00000153/Gesundheit_und_Krankheit_ im_Alter.pdf\%3Bjsessionid=756BDD3B1DEDADFFE9C287CA 17413B89 (Stand 25.10.2018)

Brenner, W., \& Uebernickel, F. (Ed.) (2016). Design Thinking for Innovation. London: Springer.

Chan, M.Y., Haber, S., Drew, L.M., \& Park, D.C. (2016). Training Older Adults to Use Tablet Computers: Does It Enhance Cognitive Function? Gerontologist, 56(3), 475-484. 
Chan, H.Y.L., \& Pang, S.M.C. (2010). Chan Let me talk - an advance care planning programme for frail nursing home residents. Journal of Clinical Nursing, 19, 3073-3084.

Chan, A.-W., Tetzlaff, J.M., Gøtzsche, P.C., Altman, D.G., Mann, H., Berlin, J., Dickersin, K., Hróbjartsson, A., Schulz, K.F., Parulekar, W.R., Krleža-Jerić, K., Laupacis, A., \& Moher, D. (2013). SPIRIT 2013 Explanation and Elaboration: Guidance for protocols of clinical trials. BMJ, 346, e7586.

Chiang, K.J., Chu, H., Chang, H.J., Chung, M.H., Chen, C.H., Chiou, H.Y., \& Chou, K.R. (2010). The effects of reminiscence therapy on psychological well-being, depression, and loneliness among the institutionalized aged. International journal of geriatric psychiatry, 25(4):380-388.

Cohn, M. (2009). Succeeding with Agile: Software development using Scrum. Upper Saddle River, N.J.: Addison Wesley.

Collani, G. v., \& Herzberg, P.Y. (2003). Eine revidierte Fassung der deutschsprachigen Skala zum Selbstwertgefühl von Rosenberg. Zeitschrift für Differentielle und Diagnostische Psychologie, 24, 3-7.

Conrad, I., Matschinger, H., Kilian, R., \& Riedel-Heller, S. (2016). WHOQOL-OLD und WHOQOL-BREF - Handbuch für die deutschsprachigen Versionen der WHO-Instrumente zur Erfassung der Lebensqualität im Alter. Göttingen: Hogrefe.

Damodaran, L., Olphert, C.W., \& Sandhu, J. (2014). Falling off the bandwagon? Exploring the challenges to sustained digital engagement by older people. Gerontology, 60(2), 163-73.

Delello, J.A., \& McWhorter, R.R. (2017). Reducing the Digital Divide: Connecting Older Adults to iPad Technology. Journal of Applied Gerontology;36(1), 3-28.

DIN ISO 9241-210. (2010). Ergonomie der Mensch-System-Interaktion - Teil 210: Prozess zur Gestaltung gebrauchstauglicher interaktiver Systeme (ISO 9241-210:2010).

Dixon, D., \& Johnston, M. (2010). Health behaviour change competency framework: Competences to deliver interventions to change lifestyle behaviours that affect health. Retrieved from http://www. healthscotland.com/documents/4877.aspx_(Stand 04.10.2018)

Djernes, J.K. (2006). Prevalence and predictors of depression in populations of elderly: a review. Acta psychiatria Scandinavia, 113(5), 372-387.

Doh, M. et al. (2016). Neue Technologien im Alter - Ergebnisbericht zum Forschungsprojekt „FUTA“. Heidelberg: Abteilung für Psychologische Alternsforschung des Psychologischen Instituts der Universität Heidelberg.

Dozeman, E., Van Marwijk, H., Van Schaik, D., Smit, F., Stek, M., Van der Horst, H., ... Beekman, A. (2012). Contradictory effects for prevention of depression and anxiety in residents in homes for the elderly: A pragmatic randomized controlled trial. International Psychogeriatrics, 24(8), 1242-1251.

Drageset, J., Kirkevold, M., \& Espehaug, B. (2011). Loneliness and social support among nursing home residents without cognitive impairment: a questionnaire survey. International Journal of Nursing Studies, 48(5), 611-619.

Ercan-Sahin, N., \& Nuran Emiroglu, O. (2017). Quality of life of nursing home residents before and after reminiscence therapy. Educational Gerontology, 44(2-3), 99-107.
Folstein, M.F., Folstein, S.E., McHugh, P.R., Kessler, J., Denzler, P., \& Markowitsch, H.J. (1990). MMST - Mini-Mental-Status-Test. Weinheim: Beltz Test GmbH.

Fraher, A., \& Coffey, A. (2011). Older peoples experiences of relocation to long-term care. Nursing Older People, 23, 23-27.

Frennert, S., \& Östlund, B. (2017). What happens when seniors participate in new eHealth schemes? Disability and Rehabilitation. Assistive Technology, 11(7), 572-80.

Freudenstein, U., Jagger, C., Arthur, A., \& Donner-Banzhoff, N. (2001). Treatments for late life depression in primary care $\mathrm{d}$ a systematic review. Family Practice ,18(3), 321-327.

Gaboda, D., Lucas, J., Siegel, M., Kalay, E., \& Crystal, S. (2011). No longer undertreated? Depression diagnosis and antidepressant therapy in elderly long-stay nursing home residents, 1999 to 2007. Journal of the American Geriatrics Society, 59(4), 673-680.

Gereben, C., \& Kopinitsch- Berger, S. (1998). „Auf den Spuren der Vergangenheit“. Anleitung zur Biographiearbeit mit älteren Menschen“. Wien, München, Bern: Wilhelm Maudrich.

Gibson, F. (2011). Reminiscence and Life Story Work. London: Jessica Kingsley Publishers.

Gothelf, J. (2012). Applying Lean Principles to Improve User Experience. Sebastopol: O'Reilly Media.

Gudjons, H. (2008). Handlungsorientiert lehren und lernen. Schüleraktivierung, Selbsttätigkeit, Projektarbeit. Bad Heilbrunn: Julius Klinkhard.

Häger., Kowark, T., Krüger, J., Vetterli, C., Übernickel, F., \& Uflacker, M. (2015). DT@ Scrum: Integrating Design Thinking with Software Development Processes. In H. Plattner, C. Meinel \& L. Leifer (Ed.), Design thinking research (pp. 263-289). Understanding innovation. Cham: Springer International Publishing.

Haight, B.K., \& Michel, Y., Hendrix, S. (2000). The extended effects of the life review in nursing home residents. International Journal of Aging and Human Development, 50(2), 151-168.

Haslam, C., Haslam, S.A., Jetten, J., Bevins, A., Ravenscroft, S., \& Tonks, J. The social treatment: the benefits of group interventions in residential care settings. Psychology and aging, 25, 157-167.

Hoffmann, T.C., Glasziou, P.P., Boutron, I., Milne, R., Perera, R., Moher, D., et al. (2014). Better reporting of interventions: template for intervention description and replication (TIDieR) checklist and guide. BMJ, 34, g1687.

Horvath, A.O., \& Bedi, R.P. (2002). The alliance. In J.C. Norcross (Ed.), Psychotherapy relationships that work: Therapist contributions and responsiveness to patients (pp. 37-69). New York, NY, US: Oxford University Press.

Housden,S. (2009). The use of reminiscence in the prevention and treatment of depression in older people living in care homes: A literature review. Groupwork, 19(2), 28-45.

Kaiser, P, \& Eley, R. (2016). Life Story Work With People with Dementia. London: Jessica Kingsley Publishers.

Keister, K.J. (2006). Predictors of self-assessed health, anxiety, and depressive symptoms in nursing Home residents at week 1 postrelocation. Journal of Aging and Health, 18(5),722-742.

Korte, J., Westerhof, G.J., \& Bohlmeijer, E.T. (2012). Mediating processes in an effective life-review intervention. Psychology and Aging, 27(4), 1172-1181. 
Lindenberger, U., Smith, J., Mayer, K.U., \& Baltes, P.B. (2010). Die Berliner Altersstudie (Vol. 3. erw. Aufl.). Berlin: Akademie Verlag.

Lomas, J., Pickard, L., Bester, S., Elbard, H., Finlayson, A., \& Zoghaib, C. (1989). The communicative effectiveness index: development and psychometric evaluation of a functional communication measure for adult aphasia. Journal of Speech and Hearing Disorders, 54(1), 113-124.

Luanaigh, C., \& Lawlor, B.A. (2008). Loneliness and the health of older people. International Journal Geriatric Psychiatry, 23(12), 1213-1221.

Mahoney, F.I., \& Barthel, D.W. (1965). Functional evaluation: The Barthel Index. Maryland State Medical Journal, 14, 61-65.

Mayer, K.U., \& Baltes, P.D. (1999). Die Berliner Altersstudie. Berlin: Akademie Verlag.

Mayring, P. (2015). Qualitative Inhaltsanalyse. Weinheim: Beltz.

Meeks, S., \& Depp, C.A. (2003). Pleasant Events-Based Behavioral Intervention for Depression in Nursing Home Residents. Clinical Gerontologist, 25(1-2), 125-148.

Menn, L., Corsten, S., Lauer, N., \& Wallace, S. (2019). Biographical approaches to improve Quality of Life of elderly in long-term care: a systematic review. Gerontologist. doi: 10.1093/geront/gnz074. [Epub ahead of print]

Molich, R. et al. (2018). CPUX-F Curriculum und Glossar. https://uxqb. org/wp-content/uploads/documents/CPUX-F_DE_Curriculumund-Glossar.pdf (Stand: 04.10.2018).

Mosher-Ashley, P.M., \& Lemay, E.P. (2001). Improving residents' life satisfaction. Nursing homes, 50(5), 50-54.

Moser, U. (2000). Identität, Spiritualität und Lebenssinn. Studien zur Theologie und Praxis der Seelsorge. Würzburg: Echter Verlag.

Nordheim, J., Hamm, S., Kuhlmey, A. \& Suhr, R. (2015). Tablet computers and their benefits for nursing home residents with dementia: Results of a qualitative pilot study. Zeitschrift für Gerontologie \& Geriatrie, 48(6), 543-549.

Roos, V., \& Malan, L. (2012). The role of context and the interpersonal experience of loneliness among older people in a residential care facility. Global Health Action, 5, 1-10

Ruhland, R. (2006). Sinnsuche und Sinnfindung im Alter als geragogische Herausforderung. Berlin: Lit-Verlag.

Saunders, J.C., \& Heliker, D. (2008). Lessons learned from 5 women as they transition into assisted living. Geriatric Nursing, 29(6), 369-375.

Schäufele, M., Köhler, L., Hendlmeier, I., Hoell, A. \& Weyerer, S. (2013). Prävalenz von Demenzen und ärztliche Versorgung in deutschen Pflegeheimen: eine bundesweite repräsentative Studie. Psychiatrische Praxis, 40(4), 200-206.

Shahar, S., Hassan, J., Sundar, V.V., Kong, A.Y., Ping Chin, S., Ahmad, S.A., \& Kuan, L.L. (2011). Determinants of depression and insomnia among institutionalized elderly people in Malaysia. Asian Journal of Psychiatry, 4(3), 188-195.

Sheikh, J.I., \& Yesavage, J.A. (1986). Geriatric Depression Scale (GDS). Recent evidence and development of a shorter version. In T.L. Brink (Ed.), Clinical Gerontology: A Guide to Assessment and Intervention (pp. 165-173). NY: The Haworth Press, Inc.
Specht-Tomann, M. (2009). Biographiearbeit in der GesundheitsKranken- und Altenpflege. Heidelberg: Springer.

Statistisches Bundesamt (2017). Pflegestatistik 2015. Retrieved from: https://www.destatis.de/DE/Publikationen/Thematisch/ Gesundheit/Pflege/PflegeDeutschlandergebnisse5224001159004. pdf?_blob=publicationFile (Stand 25.10.2018)

Syed Elias, S.M., Sharifah, M., Neville, C., \& Scott, T. (2015). "The effectiveness of group reminiscence therapy for loneliness, anxiety and depression in older adults in long term care: A systematic review." Geriatric Nursing, 36(5), 372-380.

Warfel, T.Z. (2009). Prototyping: A Practitioner's Guide (1st ed.). Rosenfeld Media.

Weyerer, S., \& Bickel, H. (2007). Epidemiologie psychischer Erkrankungen im höheren Lebensalter. Kohlhammer: Stuttgart.

Wiendieck, G. (1970). Entwicklung einer Skala zur Messung der Lebenszufriedenheit im höheren Lebensalter. Zeitschrift für Gerontologie, 3, 215-224. 